\title{
Stressful Life Events and Risk of Colorectal Cancer: A Case- Control Study of Iran
}

\author{
Hosein Azizi ${ }^{1,2}$, Elham Davtalab Esmaeili ${ }^{3 *}$
}

\begin{abstract}
Background: Very few analytical studies are available on any association between stressful life events (SLE) and colorectal cancer (CRC), at least in Iran. The aim of this case control study was to determine the association between stressful life events (SLE) and colorectal cancer. Materials and Methods: This study was conducted in four hospital colonoscopy units in Tabriz city of Iran including 414 participants aged 40-75 years: 207 cases with CRC confirmed by pathology and colonoscopy findings and 207 controls free of neoplastic conditions were selected (from the same hospitals at the same period for the cases and after matching for age and sex). Stressful life events were assessed using a 43-item Holmes and Rahe Life Events Questionnaire. Multivariate logistic regression was used to estimate adjusted odds ratios for SLE and risk of CRC. Results: The stressful life event mean score in the case group was 141.3 , in contrast to 63.8 in the control group $(p<0.011)$. After adjusting for confounders, death of dear ones increased the risk of CRC (OR: 2.49; 95\% CI: 1.41-5.13). Other types of stressful life events (family and husband disputes, serious occupational problems, unemployment of $>6$ months, and Serious financial problems) were also associated with $\mathrm{CRC}$, but without statistical significance. Conclusions: According to our findings, it seems that SLE may increase the risk of CRC.
\end{abstract}

Keywords: Stressful life events - colorectal cancer - case control study - odds ratio - Iran

Asian Pac J Cancer Prev, 16 (6), 2403-2407

\section{Introduction}

Colorectal cancer (CRC) is the third most common malignancy in the world (Iravani et al., 2014; Center et al., 2009). Among the Gastrointestinal cancers are most common cancers. Therefore, that it includes the 38 percent of cancers of the gastrointestinal system (Pourfarzi et al., 2012; Amoori et al., 2014). The highest rates of (CRC) have observed in developed countries, mostly in Western industrial and urban areas. In the United States (CRC) is second leading cause of cancer related deaths (Siegal et al., 2012). The incidence rate of (CRC) in Asia is lower than Europe, Australia, New Zealand and North America (Jemal et al., 2011). Japan and China have the highest incidence rates of colorectal cancer in Asia (Ganesh et al., 2009).

Among Iranians, CRC is the third and fourth most commonly diagnosed malignancy in males and females, respectively. In the last few decades, the incidence and mortality rates of CRC have increased markedly in Iran (Mousavi et al., 2008; Kolahdoozan et al., 2010; Somi et al., 2014). Colorectal cancer is a multi-factorial disease; several risk factors have been associated with colorectal cancer, including genetics, dietary pattern, physical activity, smoking, obesity, stressful life events and hormonal factors (World cancer., 1997; Giovannucci,. 2002; Liang et al,. 2009; Ashktorab et al., 2013; Safari et al., 2013; Iravani et al., 2014).

Stressful life events (SLE), increasing in global prevalence, has shown risk factors similar to those associated with colorectal cancer. Most of the existing findings on the association between SLE and CRC generated from studies in Western societies (Smith et al.,2010) their number is low, and most of them are crosssectional studies (Courtney et al., 1993). Since, very few analytical studies are available on the association between stressful life events (SLE) and colorectal cancer at least in Iran, is a developing country. The aim of this case control study was to determine the association between stressful life events (SLE) and colorectal cancer.

\section{Materials and Methods}

Study design and sampling

This case-control study conducted from April 2013 through March 2014 in colonoscopy units of the Cancer Institute of government hospitals in East Azerbaijan Province, Iran. The sample size was determined based on 
the information derived from a similar study (Courtney et al., 1993; Dehganzadeh et al., 2012). Considering a confidence level of $95 \%, \alpha=0.05 \%, \beta=0.2, O R=2, P 0=0.3$ and using formula:

$$
\mathrm{n}=\frac{\left[\mathrm{z}_{1-\frac{\alpha}{2}} \sqrt{2 \bar{p}(1-\bar{p})}+\mathrm{z}_{1-\beta} \sqrt{p_{0}\left(1-p_{0}\right)+p_{1}\left(1-p_{1}\right)}\right]^{2}}{\left(p_{1}-p_{0}\right)^{2}}
$$

350 samples was calculated. We oversampled at study $18 \%$ due to reduced random error (414 subjects were chosen).

\section{Subjects (cases and controls)}

The study population was patients came to colonoscopy units. 414 participant aged 40-75 years old in this study, 207 cases with CRC confirmed by pathology and colonoscopy findings were selected, diagnosed no longer than six months before the interview and 207 controls Free of neoplastic conditions and diet related chronic diseases (from the same hospital at the same period for the cases). Patients with CRC were group matched with subjects in the control group by age (within 10-years categories) and sex. From 512 patients (236 cases and 276 controls) screened for the study based on inclusion and exclusion criteria, 69 controls and 29 cases were excluded.

\section{Inclusion and Exclusion criteria}

Inclusion criteria were age 40-75 years old, CRC confirmed for the cases, free findings CRC for the controls and informed consent. Exclusion criteria were age above 75 years old and below 40 years old, neoplastic conditions, history of depression and Mental and nervous diseases and diet related chronic diseases for controls.

\section{Stressful life events (SLE) assessment}

The Holmes and rahe Life Events Questionnaire (Holmes et al., 1967) assessed stressful life events. This questionnaire (LEQ) is a 43-item self report survey that lists common life events including death of dears (child, father and mother, spouse, and first- degree family), unemployment of $>6$ months, family and spouse disputes, serious financial and occupational problems. All life events were report that subjects of study (cases and controls) experienced during at least one year ago. The validity of this questionnaire has been confirm to assess stressful life events (Vafaii., 2000) and has been use in several studies (Coteau et al., 2003). In addition, epidemiologist, statistician and psychiatrist confirmed questionnaire and some questions were revised. The reability of questionnaire $(\alpha=0.762)$ was checked by Cronbach's Alpha test.

Statistical analysis

Data analyzed by SPSS (version 16.0, Chicago, IL, USA). Kolmogorov-Smirnov test was used for check of data normality. Descriptive statistics conducted in order to

Table 1. Characteristics of Case and Control Groups with the Risk of Colorectal Cancer

\begin{tabular}{|c|c|c|c|c|}
\hline \multicolumn{2}{|l|}{ Variables } & \multirow{2}{*}{$\begin{array}{l}\text { Control } \\
(\mathrm{N}=207) \mathrm{n} \% \\
59.51 \pm 13.73\end{array}$} & \multirow{2}{*}{$\begin{array}{l}\text { Case } \\
(\mathrm{N}=207) \mathrm{n} \% \\
60.54 \pm 13.23\end{array}$} & \multirow{2}{*}{$\frac{* * \mathrm{P} \text { - value }}{*}$} \\
\hline Age (years) & & & & \\
\hline & Male $(\mathrm{M} \pm \mathrm{SD})$ & $57.48 \pm 12.8$ & $58.96 \pm 12.36$ & \\
\hline & Female $(\mathrm{M} \pm \mathrm{SD})$ & & & \\
\hline \multirow[t]{2}{*}{ Gender } & Male & $108(52)$ & $112(54)$ & $*$ \\
\hline & Female & $99(48)$ & $95(46)$ & \\
\hline \multirow[t]{3}{*}{ Body mass index(BMI) } & $\geq 24.9$ & $75(36)$ & $66(31.8)$ & \\
\hline & $25-2939$ & $93(45)$ & $103(50)$ & \\
\hline & $\leq 30$ & $39(19)$ & $38(18)$ & \\
\hline \multirow[t]{2}{*}{ Residence } & Urban & $144(69.5)$ & $158(76)$ & 0.25 \\
\hline & Rural & $63(30.5)$ & $49(24)$ & \\
\hline \multirow[t]{3}{*}{ Level of education } & No education/ Elementary & $131(67.6)$ & $140(67.6)$ & 0.72 \\
\hline & Junior/ Senior or high school & $57(27.5)$ & $36(17.4)$ & \\
\hline & Diploma/College/ University & $19(9.2)$ & $31(15)$ & \\
\hline \multirow[t]{5}{*}{ Occupation } & Self- employed & $24(11.6)$ & $24(11.6)$ & 0.3 \\
\hline & Housewife & $109(52.65)$ & $71(34.3)$ & \\
\hline & Employed/ Government & $24(11.6)$ & $28(13.5)$ & \\
\hline & Employed/ Private & $38(18.4)$ & $55(26.5)$ & \\
\hline & Retired & $12(5.8)$ & $29(14)$ & \\
\hline \multicolumn{2}{|c|}{ Family history of CRC in first degree } & $28(13.5)$ & $58(28)$ & 0.001 \\
\hline \multicolumn{2}{|l|}{ History of Diabetes } & $21(10.2)$ & $48(23.2)$ & 0.006 \\
\hline \multicolumn{2}{|l|}{ History of Hypertension } & $77(37)$ & $76(36.7)$ & 0.81 \\
\hline \multirow[t]{4}{*}{ Smoking status } & Never & $142(68.5)$ & $169(81.6)$ & 0.14 \\
\hline & Former smoker & $23(11)$ & $32(15.45)$ & \\
\hline & Current smoker (times/week) $<20$ & $13(6.3)$ & $16(7.7)$ & \\
\hline & Current smoker (times/week) $\geq 20$ & $17(8.2)$ & $2(1)$ & \\
\hline \multirow[t]{2}{*}{ Smoking hookah } & Yes & $8(3.8)$ & $10(4.8)$ & 0.4 \\
\hline & No & $199(96)$ & $197(95.2)$ & \\
\hline \multirow[t]{3}{*}{ Physical activity } & Never & $70(33.8)$ & $88(42.5)$ & \\
\hline & 1-2 times/week & $118(57)$ & $113(45.5)$ & \\
\hline & $\leq 3$ times/week & $19(9.2)$ & $6(3)$ & \\
\hline
\end{tabular}

*Matched variables; ** Using chi-square, t-test was used difference between case and control groups 
Table 2. Results of Multivariate Logistic Regression Model for Crud and Adjusted Odds Ratios and 95\% Confidence Intervals for Colorectal Cancer and Stressful Life Events Types

\begin{tabular}{|c|c|c|c|c|}
\hline Stressful life events type & $\begin{array}{c}\text { Case } \mathrm{n}(\%) \\
\mathrm{N}=207\end{array}$ & $\begin{array}{c}\text { Control n (\%) } \\
\mathrm{N}=207\end{array}$ & $\begin{array}{l}\text { Crud OR } \\
(95 \% \text { CI })\end{array}$ & **Adjusted OR \\
\hline *Death of dears & $50(24.16)$ & $24(11.6)$ & $2.42(1.38-4.32)$ & $2.49(1.41-5.13)$ \\
\hline $\mathrm{P}$-value & & & 0.009 & 0.006 \\
\hline Unemployment of $>6$ months & $8(3.87)$ & $7(3.38)$ & $1.14(0.35-3.8)$ & $1.56(0.33-3.7)$ \\
\hline P-value & & & 0.79 & 0.66 \\
\hline Family and husband disputes & $22(10.63)$ & $12(5.8)$ & $1.93(0.88-4.4)$ & $1.84(0.79-4.01)$ \\
\hline P-value & & & 0.072 & 0.11 \\
\hline Serious occupational problems & $28(13.53)$ & $18(8.7)$ & $1.64(0.84-3.26)$ & $1.8(0.92-3.86)$ \\
\hline P-value & & & 0.116 & 0.093 \\
\hline Serious financial problems & $11(5.32)$ & $9(4.35)$ & $1.23(0.45-3.45)$ & $1.12(0.39-2.98)$ \\
\hline P-value & & & 0.646 & 0.72 \\
\hline
\end{tabular}

*Including death of child, parents, spouse and first-degree families; **Adjusted OR for age, sex, Family history of CRC, history of diabetes, smoking, physical activity and BMI (Body mass index) in the Logistic regression model

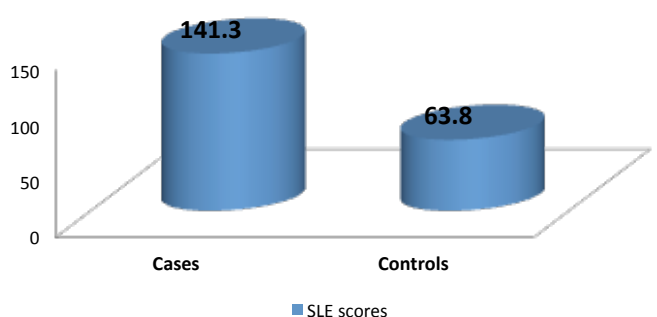

Figure 1. Comparison of Stressful Life Events Scores* Mean in Case and Control Groups, *T- test

mean compared between two groups of case and control. Independent t-test was applied for comparing for stressful life events scores mean between two groups. Chi-square $\left(\chi^{2}\right)$ test used to assess the associations between diabetes and other qualitative variables and risk of CRC.

Multiple logistic regression was used to estimate the adjusted odds ratios (OR) and removing confounding variables and identify the most important factors including death of dears (child, father and mother, spouse, and firstdegree family), Unemployment of $>6$ months, Family and husband disputes, serious financial and occupational problems affecting in the risk of colorectal cancer. In the all tests $95 \%$ confidence interval and $\mathrm{P}$-value $<0.05$ was considered significant.

\section{Ethical considerations}

The Regional Ethics Committee of University Ilam and treatment management of Tabriz University of medical sciences- Iran, approved the study protocol, Verbal informed consents were obtain from all respondent prior to the interviews.

\section{Results}

Table 1 shows the socio- demographic characteristics of participants (414 subjects). The study population (207 cases and 207 controls) included $46.85 \%$ (194) females and $53.14 \%$ (220) males. The mean age of respondents at diagnosis of colorectal cancer (CRC) was 60.54 years for men and 58.96 years for women.

Figure 1 shows that stressful life events scores mean in case group is 141.3 while its 63.8 reported in control group. The result of T-test showed that there are significant relationship between scores of stressful life events in case and control groups $(\mathrm{p}<0.011)$. Table 2 shows the results of multivariate logistic regression model for Crud and adjusted odds ratios and 95\% confidence intervals for colorectal cancer and stressful life events types. After adjusting for the age, sex, Family history of CRC, history of diabetes, smoking, physical activity and BMI (body mass index), death of dears increased the risk of CRC 2.5 times (OR: 2.49; 95\%CI: 1.41-5.13). Other types of stressful life events (family and husband disputes, serious occupational problems, Unemployment of $>6$ months, and Serious financial problems) were associated with CRC, but not statistically significant.

\section{Discussion}

This study demonstrated after adjustment of sociodemographic and other confounding variables stressful life events are associated risk of colorectal cancer. The results of this study clearly showed that the risk of colorectal cancer is associated with stressful life events and scores of cases were significantly higher than controls.

The largest odds ratio observed was associated with death of dears and increased the risk of CRC. In the present study death of dears were including death of child, spouse, parents and first-degree family. This relation observed in other case control studies. In a case, control study in Stockholm (Courtney et al., 1993) death of a spouse was increased the risk of CRC 1.5 times and this risk in our study was 2.49 times. Because the most of the events in this study were not common in study subjects, odds ratio estimates may be not very accurate, but stressful life events scores in the two groups was significant difference and increased risk of CRC.

In the general case, stressful life events scores by independent $\mathrm{T}$-test in case group were significantly higher than control group while for association between stressful life events types and CRC in multivariate regression model, only the death of dears was statistically significant association with the risk of colorectal cancer and increased the risk of colorectal cancer. In addition, other types of stressful life events (Family and husband disputes, serious occupational problems, Unemployment of $>6$ months, and Serious financial problems) were associated with CRC, 
but were not statistically significant.

A few studies has been done in the world to investigate the relationship between stressful life events and risk of colorectal cancer, but this study may be the first investigation has conducted in Iran as a developing country is quite consistent with the findings of other studies in world (Smith et al.,2010; Moreno-Smith et al., 2010). Stressful life events are associated with other cancers and increase the risk of them (Tas et al., 2012; Lillberg et al., 2014). In a Stockholm case-control, study of Courtney and colleagues who were performed contact 569 cases and 510 controls demonstrated death of dears and spouse was significantly associated with an increased risk of colorectal cancer. This is consistent with the findings of our study. Even in animal studies as well as the associated viewsin some studies, restraint-stressed mice demonstrated significantly reduced inflammatory responses to influenza virus and depressed antiviral cellular immunity (Nukina et al., 2001)

In courtney and colleagues study a history of serious work-related problems in the prior 10 years was strongly associated with the occurrence of colorectal cancer also in this study serious work-related problems was associated with the CRC but was not statistically significant. In a large population based case control study in Australia, kune et al (Kune et al., 1991) found occupational problems in the prior 5 years to have the largest effect on the risk of CRC.

The causal mechanisms that stressful life events can cause cancer is still unclear exactly. However, there is evidence that show that stressful life events can cause cancer or at least speed up the process of creating it (Segertrom et al., 2004; Moreno-Smith et al., 2010). The body responds to physical, mental, or emotional pressure by releasing stress hormones (such as epinephrine and nor epinephrine) that increase blood pressure, speed heart rate, and raise blood sugar levels. Research has shown (Lutgendorf et al., 2010) that people who experience intense and long-term (i.e., chronic) stress can have digestive problems, fertility problems, urinary problems, and a weakened immune system. People who experience chronic stress are also more prone to viral infections such as the flu or common cold and to have headaches, sleep trouble, depression, and anxiety.

Apparent links between psychological stress and cancer could arise in several ways. For example, people under stress may develop certain behaviors, such as smoking, overeating, or drinking alcohol, which increase a person's risk for cancer. Or someone who has a relative with cancer may have a higher risk for cancer because of a shared inherited risk factor, not because of the stress induced by the family member's diagnosis (Solan et al., 2010). Evidence from experimental studies does suggest that psychological stress can affect a tumor's ability to grow and spread. For example, some studies have shown that when mice bearing human tumors were kept confined or isolated from other mice-conditions that increase stress-their tumors were more likely to grow and spread (metastasize)(Lutgendorf et al., 2005; Lutgendorf et al., 2011; Fashoyin-Aje et al., 2012).

As well as some studies has been carried out the effect of group therapy on psychological symptoms and quality of life and the role of attachment dimensions on social and psychological adjustment to cancer and to explore the social and psychological adjustments, and medical adherence, among patients (Ogce et al., 2007; Yilmaz et al., 2014). In Turkish study (Yavuzsen et al., 2012) demonstrated that brief, predominantly group therapy is feasible for patients with breast cancer and, also it may be helpful to cope with emotional and physical distress. In the present study were excluded patients who had a history of depression and Mental and nervous diseases to remove the effect of confounding factors. Also in this study, as well as stressful life events increased risk of CRC, especially in cases of stress scores were significantly higher than controls.

Our study has some limitations. First, because the most of the events in this study were not common in study subjects, odds ratio estimates may be not very accurate, but stressful life events scores in the two groups was significant difference and increased risk of CRC. Second, we tried to reduce recall biases by choosing those who were not diagnosed CRC more than last 6 months of cancer diagnosis. Another limitation was selection bias; to minimize this problem by selection of cases and controls with a common referral basis (colonoscopy units) and matching the cases and controls by age and sex and using of logistic regression models and adjusted ORs.

In conclusion, after multivariate adjusting for the confounders, according to our findings, it seems that stressful life events (SLE) increase the risk of CRC. Therefore, appropriate and reasonable efforts to exposure with the stressful life events and attempts to reduce this stresses can be an effective step way prevention of colorectal cancer.

\section{Acknowledgements}

This study taken from a thesis in MSc of Epidemiology student and was funded by research management of Ilam University of Medical Science. The authors thank the Research management of Ilam University of Medical Science and treatment management of Tabriz University, and patients for their participation and cooperation in the study.

\section{References}

Amoori N, Mirzaei M, Cheraghi M (2014). Incidence of cancers in Kuzestan Province of Iran: trend from 2004 to 2008. Asian Pac J Cancer Prev, 15, 8345-49.

Ashktorab, Namin H, Taylor T, et al (2013). Role of life events in the presence of colon polyps among African Americans. BMC Gastroenterology, 13, 101-7.

Center MM, Jemal A, Ward E (2009). International trends in colorectal cancer incidence rates. Cancer Epidemiol Biomarkers Prev, 18, 1688-94.

Chen Y-S, Xu S-X, Ding Y-B, et al (2013). Colorectal cancer screening in high-risk populations: a survey of cognition among medical professionals in Jiangsu, China. Asian Pac J Cancer Prev, 14, 6487-91.

Coteau TJ, Hope DA (2003). Anxicty, stress, and health in northern plain native Americans. Behavior Therapy, 34, 365-80. 
Courtney JG, Longnecker MP, ONE MORE, et al (1993). Stressful Life Events and the Risk of Colorectal Cancer. Epidemiology, 5, 407-14.

Dehganzadeh Sh, Jafaraghai F (2012). Relationship between demographic characteristics, lifestyle and to stressor events and colorectal cancer. Med J Nurse Res, 24, 6-15.

Fashoyin-Aje LA, Martinez KA, Dy SM (2012). New patientcentered care standards from the Commission on Cancer: opportunities and challenges. J Supportive Oncol, 3, 107-11.

Ganesh B, Talole SD, Dikshit R (2009). A case-control study on diet and colorectal cancer from Mumbai, India. Cancer Epidemiol, 33, 189-93.

Giovannucci E (2002). Modifiable risk factors for colon cancer. Gastroenterol Clin North Am, 31, 925-43.

Holmes TH Rahe RH (1967). The Social Readjustment Rating Scale. J Psychosmatic Res, 11, 213-218.

Iravani SH, Kashfi M, Azimzadeh P et al (2014). Prevalence and characteristics of colorectal polyps in symptomatic and asymptomatic iranian patients undergoing colonoscopy from 2009-2013. Asian Pac J Cancer Prev, 15, 9933-37.

Jemal A, Bray F, Center MM, et al (2011). Global cancer statistics. CA Cancer J Clin, 61, 69-90.

Kolahdoozan S, Sadjadi A, Radmard AR (2010). Five common cancers in Iran. Arch Iran Med, 13, 143-6.

Kune S, Kune GA, Watson LF, et al (1991). Recent life change and large bowel cancer. Data from the melbourn cancer study. J Clin Epidemiol, 44, 57-68.

Liang PS, Chen TY, Giovannucci E (2009). Cigarette smoking and colorectal cancer incidence and mortality: systemic review and meta-analysis. Int J Cancer, 124, 2406-15.

Lillberg K, Verkasalo P, Kaprio J, et al (2014). Stressful life events and risk of breast cancer in 10,808 women: a cohort study. Am J Epidemiol, 157, 415-23

Lutgendorf SK, DeGeest K, Dahmoush L, et al (2011). Social isolation is associated with elevated tumor norepinephrine in ovarian carcinoma patients. Brain Behavior Immunity, 25, 250-5.

Lutgendorf SK, Sood AK, Anderson B, et al (2005). Social support, psychological distress, and natural killer cell activity in ovarian cancer. J Clin Oncol, 23, 7105-13.

Lutgendorf SK, Sood AK, Antoni MH (2010). Host factors and cancer progression: biobehavioral signaling pathways and interventions. J Clin Oncol, 28, 4094-9.

Moreno-Smith M, Lutgendorf SK, Sood AK (2010). Impact of stress on cancer metastasis. Future Oncology, 6, 1863-81.

Mousavi S,Alamolhoda A, Gouya M, et al (2008). Implementation of comprehensive national cancer control program in Iran: an experience in a developing country. Ann Oncol, 19, 398-400.

Nukina H, Sudo N, Aiba Y, et al (2001). Restraint stress elevates the plasma interleukin-6 levels in germfree mice. J Neuroimmunol, 115, 46-52.

Ogce F, Ozkan S, Baltalarli B (2007). Psychosocial stressors, social support and socio-demographicvariables as determinants of quality of life of Turkish breast cancer patients. Asian Pac J Cancer Prev, 8, 77-82.

Pourfarzi F, Yazdanbod A, Daneshvar R, et al (2012). Evaluation of effective factors in incidence of colorectal cancer. $J$ Ardabil Univ Med Sci, 12, 56-64.

Safari A, Mohd Shariff Z, Kandiah M, et al (2013). Dietary patterns and risk of colorectal cancer in Tehran Province: a case-control study. J BMC Public Health, 13, 222-33.

Segerstrom SC, Miller GE (2004). Psychological stress and the human immune system: a meta-analytic study of 30 years of inquiry. Psychol Bull, 130, 601-30.

Siegel R, Desantis C, Virgo K, et al (2012). Cancer treatment and survivorship statistics, 2012. CA Cancer J Clin, 62, 220-41.

Sloan EK, Priceman SJ, Cox BF, et al (2010). The sympathetic nervous system induces a metastatic switch in primary breast cancer. Cancer Research, 70, 7042-52.

Smith M, Lutgendorf S, Sood A (2010). Impact of stress on cancer metastasis. Future Oncol, 12, 1863-81

Somi M, Golzari M, Farhang S, Naghashi SH, Abdollahi L (2014). Gastrointestinal cancer incidence in East Azerbaijan, Iran: update on 5 year incidence and trends. Asian Pac J Cancer Prev, 15, 3945-49.

Tas F, Karalar U, Aliustaoglu M et al (2012). The major stressful life events and cancer: stress history and cancer. Med Oncol, 29, 1371-77.

Vafaii B (2000). [Evaluation of the relation between life stresses and blood neoplastic diseases in males and females aged between 30 and 50]. Med J Tabriz Univ Med Sci, 34, 47-54.

World Cancer Research Fund/American Institute for Cancer Research (WCRF/AICR). Food, nutrition and the prevention of cancer: a global perspective. Washington, DC: WCRF/ AICR 1997.

Yavuzsen T, Karadibak D, Cehreli R, et al (2012). Effect of group therapy on psychological symptoms and quality of life in turkish patients with breast cancer. Asian Pac J Cancer Prev, 13, 5593-97.

Yilmaz O, Ayaz T, Konag O (2014). Attachment style and perceived social support as predictors of biopsychosocial adjustment to cancer, 44, 24-30. 